\title{
PERANCANGAN MEDIA APLIKASI BUS TRANS METRO BANDUNG
}

\author{
Sheila Christy, Roy Antonius Susanto \\ (Email: sheila.sielan.99@gmail.com) \\ Desain Komunikasi Visual \\ Fakultas Seni Rupa dan Desain \\ Universitas Kristen Maranatha, \\ Jl. Prof .drg. Surya Sumantri No 65, Bandung, Indonesia
}

\begin{abstract}
ABSTRAK
Bandung sebagai salah satu kota yang berpenduduk padat membutuhkan mobilisasi untuk melakukan kegiatan sehari-hari. Dalam melakukan mobilisasi tersebut, masyarakat dapat menentukan pilihan untuk memakai transportasi pribadi ataupun transportasi publik yang telah disediakan oleh pemerintah. Trans Metro Bandung (TMB) adalah salah satu transportasi publik yang disediakan oleh pemerintah dengan fasilitas yang sudah memadai, tetapi mayoritas masyarakat sulit untuk mendapatkan informasi seputar bus TMB baik rute, jadwal, lokasi halte, maupun fasilitas bus. Hal ini dapat diatasi melalui teknologi media yang dapat mempermudah masyarakat untuk mendapatkan sekaligus berinteraksi dengan informasi tersebut. Tujuan perancangan ini adalah untuk mempermudah masyarakat dalam mencari segala informasi mengenai bus TMB melalui media aplikasi yang informatif serta terstruktur, memiliki ciri khas lokal yang disesuaikan dengan kebutuhan masyarakat Kota Bandung. Perancangan ditekankan pada pendekatan unsur User Experience dan User Interface yang pada akhirnya bertujuan untuk memudahkan masyarakat untuk mencari informasi terkait fasilitas TMB yang terintegrasi dalam satu aplikasi digital.
\end{abstract}

Kata kunci: transportasi umum; user experience; user interface

\begin{abstract}
Bandung as one city that has a dense population requires mobilization to carry out daily activities. In carrying out this mobilization, the community can choose to use private transportation or public transportation that has been provided by the government. Trans Metro Bandung (TMB) is one of the public transportation provided by the government with adequate facilities, but the majority of people find it difficult to obtain information about TMB buses, both routes, schedules, bus stops, and bus facilities. This can be overcome through media technology that can make it easier for people to get and interact with that information.The purpose of this design is to make it easier for people to find all information about TMB buses through informative and structured application media, having local characteristics that are tailored to the needs of the people of Bandung City. The design is emphasized on the element of User Experience and User Interface approach which ultimately aims to make it easier for people to find information related to TMB facilities that are integrated in 1 digital application.
\end{abstract}

Keywords: public transportation; user experience; user interface 
Serat Rupa Journal of Design, January 2019, Vol.3, No.1: 34-47

E-ISSN: 2477-586X, ISSN: 2338-3348 | https://doi.org/10.28932/srjd.v3i1.1060| Received: 02-10-2018, Accepted: 25-01-2019 Sheila Christy, Roy Antonius Susanto

Perancangan Media Aplikasi Bus Trans Metro Bandung

\section{PENDAHULUAN}

Bandung sebagai salah satu kota yang padat penduduknya tentu membutuhkan mobilisasi untuk melakukan kegiatan sehari-hari. Dalam melakukan mobilisasi tersebut masyarakat dapat memilih untuk menggunakan transportasi pribadi maupun transportasi publik. Trans Metro Bandung (TMB) adalah salah satu transportasi publik yang disediakan oleh pemerintah dan sedang dikembangkan ke depannya menjadi salah satu transportasi umum utama. Bahkan menurut Walikota Bandung (okezone.com,2016) Ridwan Kamil mengatakan bahwa 2-3 jalur angkutan umum diubah menjadi jalur bus. Namun, menurut hasil survei yang dilakukan Penulis kepada 130 masyarakat dewasa muda di Kota Bandung pada bulan Februari 2018, 74.1\% masyarakat lebih banyak menggunakan transportasi pribadi. Di antara transportasi publik yang ada di Kota Bandung, 60.7\% masyarakat mengaku paling sering menggunakan transportasi berbasis aplikasi online. Sedangkan bus TMB hanya sering digunakan oleh 1.5\% masyarakat di Kota Bandung. Tentunya hasil survei ini menimbulkan pertanyaan mengapa bus TMB tidak sering digunakan oleh masyarakat Kota Bandung padahal sudah layak untuk digunakan sebagai transportasi sehari-hari dengan fasilitas bus yang memadai. Ditemukan alasan bahwa $71.8 \%$ masyarakat tidak menggunakan bus TMB sebagai transportasi sehari-hari karena masyarakat sulit mendapatkan informasi seputar bus TMB baik rute, jadwal, lokasi halte maupun fasilitas bus. Hal ini disayangkan karena perkembangan teknologi saat ini dapat mempermudah masyarakat untuk mendapatkan informasi tersebut dan TMB belum memanfaatkan teknologi secara maksimal. Hal tersebut didukung data kuesioner, 42.8\% masyarakat mengetahui informasi hanya dari hasil mulut ke mulut. Diperkuat dengan hasil wawancara yang dilakukan Penulis kepada Bapak Taufik selaku bagian Manajemen Transportasi dan Parkir (MTP) divisi angkutan umum yang sudah bekerja selama lima tahun di DISHUB Kota Bandung. Bapak Taufik (2018) mengungkapkan bahwa penyampaian informasi lebih banyak dari hasil mulut ke mulut atau sosialisasi di dalam bus dan penyebaran leaflet. Begitu juga hasil yang dilakukan oleh peneliti terdahulu dengan fokus kajian yang berbeda seperti pada Jurnal Politikom Indonesia menurut Indra Aditya (2016) diambil kesimpulan bahwa Pemerintah Kota Bandung menggunakan forum-forum sosialisasi, forum paparan laporan perencanaan, media massa, situs resmi, dan media sosial dalam memberikan akses informasi terkait Trans Metro Bandung dan monorel di Kota Bandung. Tetapi informasi yang diberikan belum lengkap dan belum ada mekanisme umpan balik untuk permintaan informasi dari masyarakat. Hal inilah yang menjadi latar belakang permasalahan dalam perancangan ini. Adapun target perancangan ini ditujukan pada seluruh golongan 
Serat Rupa Journal of Design, January 2019, Vol.3, No.1: 34-47

E-ISSN: 2477-586X, ISSN: 2338-3348 | https://doi.org/10.28932/srjd.v3i1.1060 | Received: 02-10-2018, Accepted: 25-01-2019 Sheila Christy, Roy Antonius Susanto

Perancangan Media Aplikasi Bus Trans Metro Bandung

masyarakat berdomisili ataupun berada di Kota Bandung yang biasanya berprofesi sebagai pelajar/mahasiswa yang terbiasa menggunakan transportasi umum untuk kegiatan seharihari.

Seiring berkembangnya teknologi seperti gawai, internet, hingga sistem berbasis online, pembayaran online (cashless) menjadi suatu hal yang utama dan tidak bisa ditinggalkan oleh masyarakat. Terlebih sudah adanya sebuah aplikasi yang berkembang dari teknologi saat ini dalam memudahkan masyarakat melakukan sebuah pencarian informasi, bermain game dan berbagai kegunaan lainnya. Oleh karena itu, aplikasi yang informatif, efektif mengenai bus TMB dengan ciri khas lokal serta sesuai dengan kebutuhan masyarakat diharapkan menjadi solusi yang tepat untuk memudahkan masyarakat dalam mencari seluruh informasi mengenai bus TMB serta memudahkan penggunaan bus TMB untuk kegiatan sehari-hari melalui gawai masing-masing.

\section{METODE PENELITIAN}

Perancangan ini dibuat berdasarkan penelitian yang dilakukan dengan metode kualitatif yaitu observasi aktif, wawancara, dan studi pustaka. Dilakukan observasi aktif sebagai tahap awal penelitian ini dengan mencoba menggunakan bus TMB. Observasi ini dilakukan dengan tujuan agar tim peneliti mengerti bagaimana rincian cara penggunaan bus TMB mulai dari mencari rute dari satu tujuan ke tujuan lain, mencari halte, menunggu kedatangan bus hingga naik bus TMB. Dalam observasi ini didapatkan berbagai macam informasi seputar rincian penggunaan bus TMB.

Wawancara dilakukan ke dua pihak terkait, yaitu pertama wawancara dengan Bapak Agus (sopir) yang sudah dua tahun menjadi sopir TMB dan Bapak Mulyono (kondektur) bus TMB. Wawancara pada sopir dan kondektur bus TMB bertujuan untuk mengetahui kondisi sehari-hari para penumpang bus TMB, memahami bagaimana situasi yang sedang dialami oleh bus TMB, serta beberapa rincian teknis rute, jadwal keberangkatan, pembayaran dan lainnya. Kedua, wawancara dengan perwakilan DISHUB Kota Bandung yaitu Bapak Taufik selaku bagian Manajemen Transportasi dan Parkir (MTP) divisi angkutan umum yang kesehariannya bekerja untuk mengawasi dan bagian operasional bus TMB. Bapak Taufik sudah bekerja dalam bidang ini selama lima tahun. Wawancara ini bertujuan untuk mencari tahu informasi perkembangan bus TMB dari awal berdiri hingga sekarang, sejarah singkat mengenai bus TMB, rincian keunggulan, kelemahan, serta kendala-kendala yang dialami 
Serat Rupa Journal of Design, January 2019, Vol.3, No.1: 34-47

E-ISSN: 2477-586X, ISSN: 2338-3348 | https://doi.org/10.28932/srjd.v3i1.1060| Received: 02-10-2018, Accepted: 25-01-2019 Sheila Christy, Roy Antonius Susanto

Perancangan Media Aplikasi Bus Trans Metro Bandung

oleh bus TMB. Selain itu juga untuk mendapatkan data yang lengkap seputar rute, daftar koridor, lokasi halte, jadwal keberangkatan, dan data pendukung lainnya dalam perancangan ini.

Studi pustaka yang mendukung penelitian dengan luaran perancangan desain ini adalah yang berhubungan dengan Teori Transportasi Umum, Definisi Bus, Media Informasi, Pengertian Infografis, Pengertian Aplikasi, dan Teori UI / UX

Teori transportasi umum digunakan untuk mengetahui fungsi sebenarnya dari transportasi umum serta pentingnya transportasi bagi masyarakat dan dapat menonjolkan fungsi tersebut dalam perancangan yang dibuat. Seperti menurut Nasution (1996), transportasi merupakan pemindahan barang dan manusia dari tempat asal ke tempat tujuan. Definisi bus berguna agar fokus dan tidak menyimpang pada masalah yang dibahas. Penulis harus mengetahui macam-macam media informasi untuk referensi media apa saja yang dapat digunakan untuk perancangan ini seperti yang dijelaskan oleh Sobur (2006) bahwa alat-alat grafis, fotografis atau elektronik untuk menangkap, memproses, serta menyusun kembali informasi visual. Penulis menggunakan pengertian infografis karena mempermudah penyampaian informasi dalam beberapa perancangan.

Beberapa pengertian aplikasi menurut para ahli serta pembahasan mengenai apa yang dimaksud dengan User Interface (UI) dan User Experience (UX). UI adalah bagaimana suatu produk yang bisa dilihat oleh mata (visible). UI lebih fokus pada visualisasi, coloring, dan halhal yang berkaitan dengan kreativitas dari interface yang akan digunakan oleh user. "UX bukan merupakan cara kerja dari suatu produk atau jasa. UX merupakan cara kerja di luar, dengan seseorang datang dan berhadapan langsung (Rofid Hilmi dan Ardiansyah, 2015)". UX lebih fokus terhadap perancangan, menjembatani bagaimana tampilan nanti mampu bekerjasama dengan melaksanakan fungsi-fungsi suatu sistem. Perancangan ini menerapkan prinsip-prinsip umum dari UI (N.Uday Bhaskar, et al, 2011).

Selain metode kualitatif, dilakukan juga metode kuantitatif berupa penyebaran kuesioner kepada 130 dewasa muda yang tinggal atau menetap di Kota Bandung. Kuesioner ini digunakan sebagai data tambahan untuk mendukung data dan fakta mengenai topik yang Penulis rancang serta membantu menentukan media apa saja yang dipakai oleh penulis. 
Serat Rupa Journal of Design, January 2019, Vol.3, No.1: 34-47

E-ISSN: 2477-586X, ISSN: 2338-3348 | https://doi.org/10.28932/srjd.v3i1.1060 | Received: 02-10-2018, Accepted: 25-01-2019 Sheila Christy, Roy Antonius Susanto

Perancangan Media Aplikasi Bus Trans Metro Bandung

\section{PEMBAHASAN}

Perancangan aplikasi bus Trans Metro Bandung memiliki banyak informasi yang harus disampaikan kepada target audience agar audience mengetahui seluruh informasi yang dibutuhkan dalam menggunakan bus Trans Metro Bandung. Aplikasi menjadi solusi untuk memecahkan masalah tersebut karena aplikasi dapat memuat beragam informasi dalam satu wadah dengan efisien. Penyampaian komunikasi yang Penulis utamakan adalah informatif dengan komunikasi yang mudah dimengerti oleh target audience. Sesuai hasil data yang telah Penulis kumpulkan, pengguna aplikasi adalah dewasa muda berusia 19-23 tahun yang memiliki gaya hidup lekat dengan penggunaan teknologi aplikasi berbasis mobile.

Maka dari itu, gaya bahasa yang digunakan dalam perancangan ini lebih bersahabat, terdapat rasa humor (menggunakan bahasa gaul) sehingga terdengar lebih akrab bagi target audience. Gaya bahasa ini digunakan baik dalam bahasa Indonesia maupun saat menggunakan bahasa Sunda. Penggunaan bahasa Sunda karena target audience yang ingin dijangkau adalah masyarakat Kota Bandung yang menjadikan bahasa Sunda sebagai bahasa daerah. Tentunya tidak semua konten yang terdapat dalam perancangan ini menggunakan bahasa Sunda, hanya beberapa bagian penting atau bagian yang sifatnya persuasif (mengajak) seperti pada bagian promosi. Hal tersebut bertujuan jika terdapat pengguna yang tidak mengerti bahasa Sunda atau pengguna yang bukan berasal dari Kota Bandung tetap dapat menggunakan aplikasi yang informatif dan mudah dimengerti.

Strategi kreatif yang digunakan oleh Penulis adalah dengan mengacu pada Human Centered Design berupa perancangan UX (User Experience) sesuai dengan kebutuhan masyarakat Kota Bandung yang berbeda karakternya dengan masyarakat di kota lain. Hal ini didasari oleh hasil User Persona yang telah Penulis olah. Penulis merancang konsep kreatif yang dibagi menjadi tiga bagian yaitu: keamanan, efektivitas, dan gamification. Pertama, penggunaan fotografi untuk menunjukkan halte beserta lokasinya agar pengguna lebih mudah mengenali tempat menunggu bus TMB, adapun visualisasi report online sehingga target audience merasa lebih aman dalam menggunakan aplikasi yang dirancang. Kedua, Penulis merancang visualisasi halte online sehingga calon pengguna tak perlu repot menunggu di halte untuk melihat kapan bus tiba, kapasitas bus, urutan kedatangan bus dan informasi lainnya karena halte yang ada di Bandung tidak terlalu besar dan tidak memiliki fasilitas untuk memonitori hal-hal yang sudah Penulis sebutkan. 
Serat Rupa Journal of Design, January 2019, Vol.3, No.1: 34-47

E-ISSN: 2477-586X, ISSN: 2338-3348 | https://doi.org/10.28932/srjd.v3i1.1060| Received: 02-10-2018, Accepted: 25-01-2019 Sheila Christy, Roy Antonius Susanto

Perancangan Media Aplikasi Bus Trans Metro Bandung

Selain itu ditambahkan dengan berbagai gamification agar target audience tertarik menggunakannya, melengkapi apa yang dibutuhkan oleh calon pengguna seperti incentive point yang digunakan untuk membuat penggunaan aplikasi lebih sering, terdapat juga mini memo untuk berbagai landmark yang dilewati penumpang selagi berkendara menggunakan bus yang memuat informasi singkat mengenai tempat tersebut, serta berbagai visualisasi seperti alarm, dan perkiraan cuaca. Seluruh konsep kreatif UX tersebut Penulis susun berdasarkan User Journey Map sehingga mudah dimengerti oleh pengguna. Sedangkan untuk UI (User Interface), Penulis mengutamakan visual yang terstruktur sehingga tampilan tidak membuat bingung calon pengguna karena jumlah informasi yang ada dalam aplikasi terbilang banyak. Selain itu, Penulis menonjolkan visualisasi yang mengandung unsur kearifan lokal seperti lanskap Kota Bandung (gunung, sungai), landmark Kota Bandung, atau budaya-budaya yang terdapat di Bandung. Penggunaan warna yang menjadi ciri khas Kota Bandung yaitu biru, putih, kuning, dan hijau.

BEUS berasal dari bahasa Sunda yang berarti 'Bus' (kendaraan beroda empat atau lebih yang memuat banyak penumpang) dalam bahasa Indonesia. Terdapat tiga elemen pada logo BEUS yaitu, pertama pada bagian bawah logotype huruf $b$, menandakan bandung yang identik dikelilingi oleh gunung. Kedua, pin point yang berada di tengah huruf $b$ menandakan bahwa aplikasi ini merupakan aplikasi navigasi. Ketiga, penggunaan warna biru, kuning, dan hijau merupakan ciri khas warna Kota Bandung dan cooperate dari bus TMB sendiri.

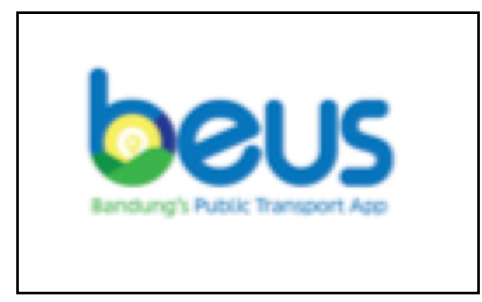

Gambar 1. Logo aplikasi BEUS

(Sumber: Dokumen Pribadi, 2018) 
Berikut wireframe dari keseluruhan tampilan aplikasi BEUS. Tanda panah merah merupakan sebuah alur dari awal user membuka aplikasi hingga memilih rute, navigasi hingga mengatur akun miliknya. Keterangan setiap fungsi akan dijelaskan sesuai dengan nomor yang ada pada wireframe.

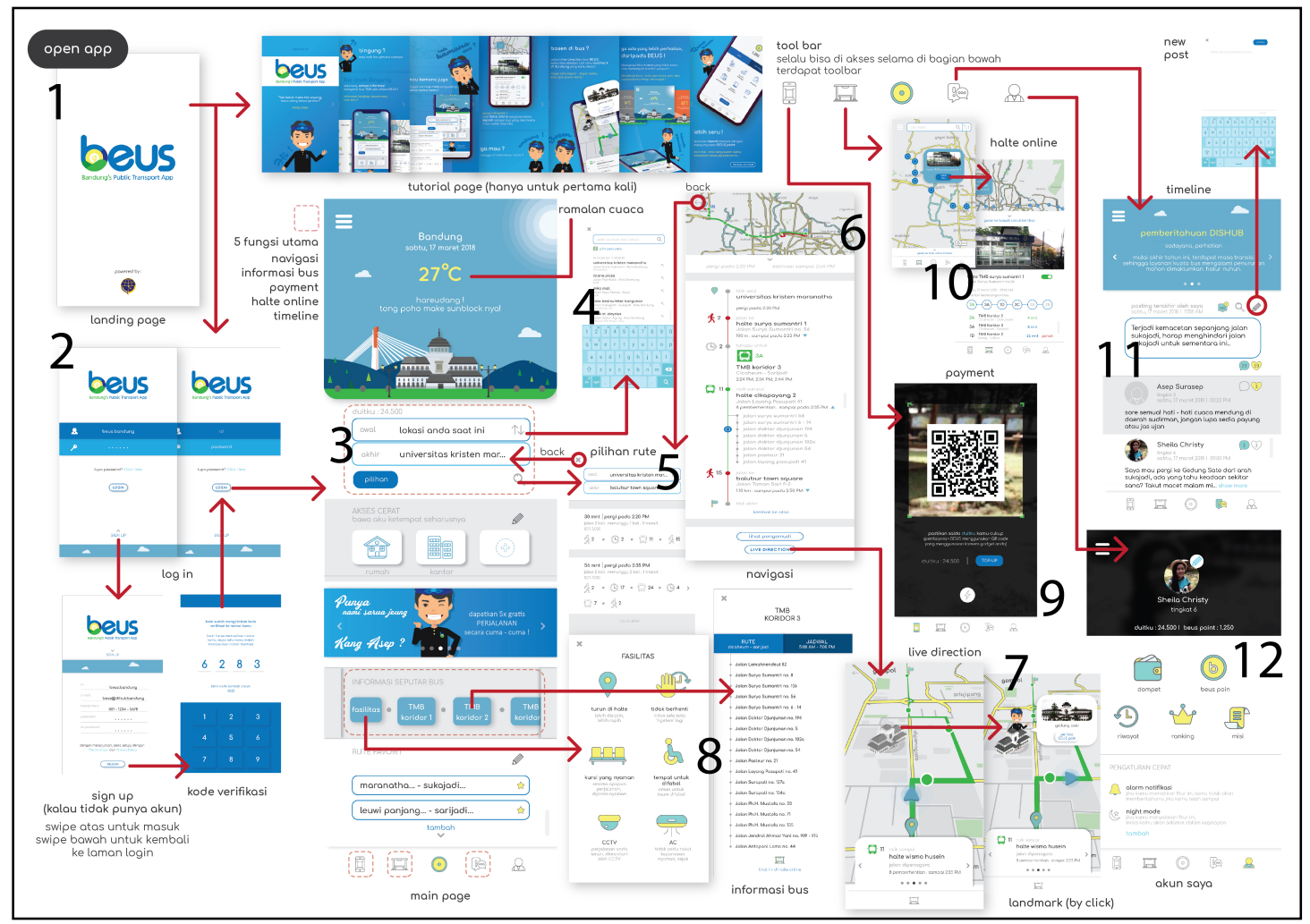

Gambar 2. Wireframe Aplikasi BEUS

(Sumber: Dokumen Pribadi, 2018)

1. Landing page merupakan tampilan yang pertama kali dilihat setelah membuka aplikasi dari gawai masing-masing. Pada landing page ini hanya terdapat logo dengan latar belakang warna putih sehingga logo lebih ditonjolkan. Landing page hanya tampil beberapa saat saja.

2. Setelah melewati landing page masuk pada bagian log-in pada bagian ini user harus memasukkan nama id dan password untuk masuk ke dalam aplikasi BEUS.

3. Setelah masuk, bagian yang paling penting adalah bagian utama. Akses untuk seluruh fitur yang ada pada aplikasi beus dapat dilewati pada bagian ini karena terdapat side menu, tool bar (pada bagian bawah) dan tombol menu lainnya dengan sistem scroll down. Sistem ini digunakan untuk mempermudah pengguna dalam mengakses. Seluruh informasi utama untuk mencari rute, halte, jadwal maupun fasilitas terdapat 
langsung pada bagian utama karena merupakan informasi yang paling diutamakan pada aplikasi ini.

Pada bagian atas terdapat ramalan cuaca yang mempermudah pengguna mempersiapkan diri sebelum menaiki bus, fitur ini disesuaikan dengan kebutuhan target audience karena tim Penulis ingin membuat aplikasi yang berdasarkan human centered design terutama untuk masyarakat kota Bandung, gaya visual menggunakan ilustrasi lanskap dan landmark yang ada di kota Bandung yang dapat disesuaikan dengan waktu serta cuaca yang sedang terjadi saat itu.

4. Berikut tampilan setiap saat mencari sebuah rute ataupun alamat. Seluruhnya dibuat sama agar mempermudah pegguna dalam mengenali bagian search.

5. Bagian ini merupakan fungsi utama dalam aplikasi beus yaitu mencari pilihan rute menggunakan bus TMB dalam bepergian. Tampilan pilihan rute dibuat terstruktur dengan piktogram yang jelas serta disusun berdasarkan tahap-tahap cara untuk sampai pada lokasi yang diinginkan. Pada bagian ini, belum ada pilihan bus yang digunakan, tetapi hanya kategori yang diinginkan masyarakat apakah untuk mengutamakan waktu yang lebih sedikit, harga yang lebih murah atau jalan lebih sedikit sehingga masyarakat lebih mudah untuk menentukan.

6. Setelah memilih rute masuk ke menu step by step. Seperti namanya bagian ini didesain lebih terstruktur sesuai tahap-tahap dalam menggunakan bus. Tahap-tahap tersebut disusun ke bawah dengan sistem scrolling. Pada bagian atas terdapat peta untuk melihat daerah mana yang dilewati dengan dilengkapi garis petunjuk yang dibagi berdasarkan warna sesuai step yang ditentukan pada bagian bawah. Sehingga pengguna lebih mudah mencari tahu rute mana yang dimaksudkan pada bagian tahap tertentu.

7. Live direction merupakan tampilan yang dibuat lebih rinci lagi karena seluruh tahap nya dibuat satu persatu tidak sekaligus berupa map dengan tampilan visual tiga dimensi seperti dalam penggunaan alat navigasi. Selain itu terdapat gamification yaitu landmark discover dengan tujuan untuk memberi informasi selama dalam perjalanan, terdapat landmark di Kota Bandung yang bisa dilewati oleh pengguna menggunakan bus TMB. Sehingga saat pengguna yang semula tidak mengetahui akan menjadi tahu, dan bila sudah tahu pengguna mendapatkan BEUS point setiap kali melewatinya. Fungsi ini juga membantu pengguna lebih tertarik pada perjalanannya jika bosan selama berada di dalam bus. 
Serat Rupa Journal of Design, January 2019, Vol.3, No.1: 34-47

E-ISSN: 2477-586X, ISSN: 2338-3348 | https://doi.org/10.28932/srjd.v3i1.1060 | Received: 02-10-2018, Accepted: 25-01-2019 Sheila Christy, Roy Antonius Susanto

Perancangan Media Aplikasi Bus Trans Metro Bandung

8. Pada bagian utama, terdapat tampilan informasi seputar bus yang memuat seluruh rute yang ada pada koridor TMB, serta fasilitas yang disediakan oleh bus TMB dan DISHUB Kota Bandung sehingga dapat dimanfaatkan secara maksimal oleh pengguna bus.

9. Pembayaran dalam aplikasi BEUS didesain lebih sederhana dengan membayar melalui gawai masing-masing, tidak perlu repot dengan uang cash ataupun bingung dengan kartu elektronik mana yang harus digunakan.

10. Terkait keberadaan halte yang belum merata di Bandung, ada yang hanya menggunakan tangga besi, ada yang tidak terurus atau rusak, membuat pengguna kebingungan dan tidak nyaman untuk menunggu di bus. Maka dari itu aplikasi BEUS mendesain sebuah halte online yang dapat digunakan pengguna untuk mencari tahu waktu kedatangan bus, bus yang aktif pada halte tersebut, halte yang harus didatangi seperti apa. Sehingga masyarakat dapat mengatur waktu sendiri kapan harus sudah menunggu di dalam halte, tidak lagi tanpa kepastian.

11. Setiap harinya, keadaan jalanan ataupun keadaan pelayanan TMB bisa saja berubahubah. Sehingga dirancang sebuah wadah tempat para pengguna dapat saling membagikan informasi mengenai keadaan jalanan di bandung dan mengetahui informasi langsung dari DISHUB kota bandung mengenai situasi yang sedang terjadi saat ini.

12. Selebihnya merupakan pengaturan untuk akun pribadi pada aplikasi.

Pada bagian "akun saya" terdapat beberapa pengaturan seperti yang pertama adalah Wallet. Sesuai dengan artinya di dalam bagian ini pengguna dapat mengatur keuangan.

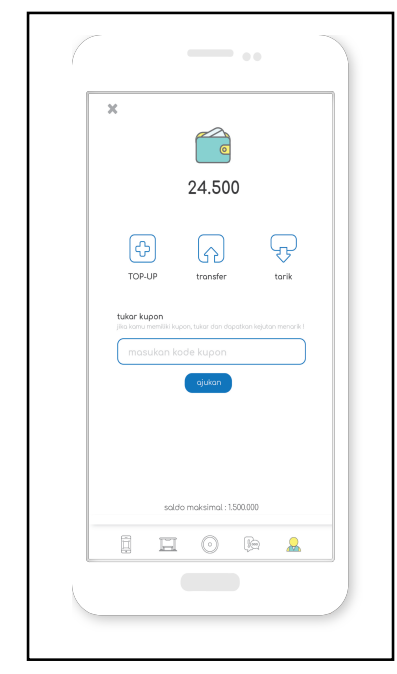

Gambar 3. Wallet

(Sumber: Dokumen Pribadi, 2018) 
Serat Rupa Journal of Design, January 2019, Vol.3, No.1: 34-47

E-ISSN: 2477-586X, ISSN: 2338-3348 | https://doi.org/10.28932/srjd.v3i1.1060| Received: 02-10-2018, Accepted: 25-01-2019 Sheila Christy, Roy Antonius Susanto

Perancangan Media Aplikasi Bus Trans Metro Bandung

Nama Incentive point yang ada pada beus adalah BEUS poin. Bagian ini dirancang dengan tujuan supaya pengguna lebih tertarik dan menggunakan aplikasi ini dalam jangka waktu yang lama. Pengguna harus mengumpulkan poin untuk menukarkannya dengan hadiah lainnnya.

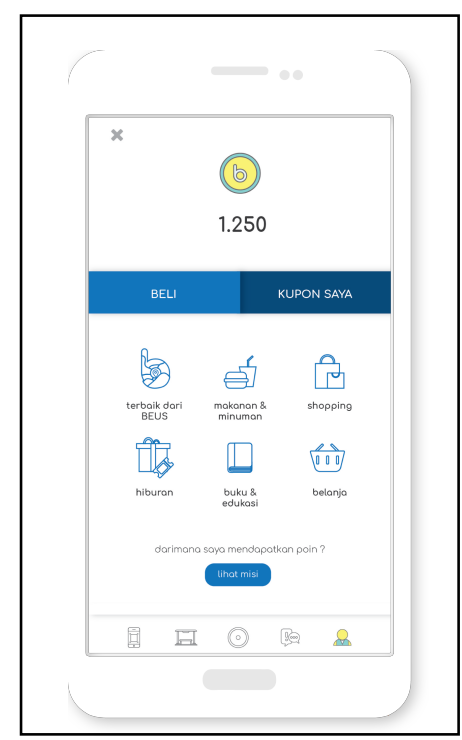

Gambar 4. BEUS poin

(Sumber : Dokumen Pribadi, 2018)

Tampilan riwayat ini dibuat terstruktur sesuai dengan waktu mulai dari yang terbaru hingga perjalanan ataupun transaksi yang paling lama, seluruhnya tercatat pada bagian ini. Khususnya, penggunaan offline access dilihat dari yang dibintangi diatur pada bagian riwayat perjalanan.

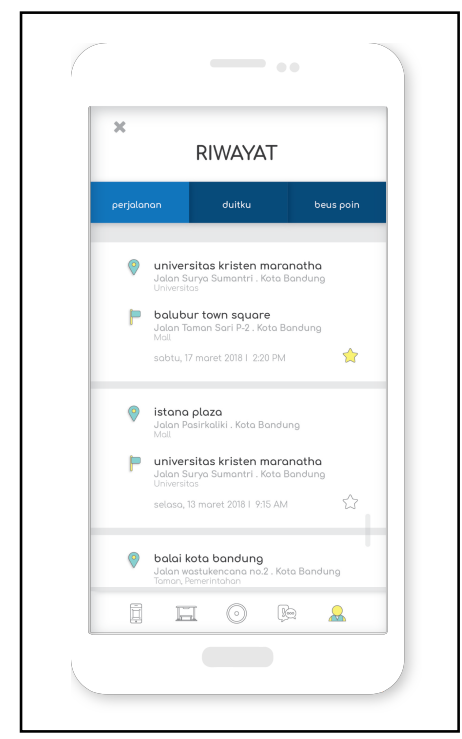

Gambar 5. Riwayat

(Sumber: Dokumen Pribadi, 2018) 
Serat Rupa Journal of Design, January 2019, Vol.3, No.1: 34-47

E-ISSN: 2477-586X, ISSN: 2338-3348 | https://doi.org/10.28932/srjd.v3i1.1060 | Received: 02-10-2018, Accepted: 25-01-2019 Sheila Christy, Roy Antonius Susanto

Perancangan Media Aplikasi Bus Trans Metro Bandung

Bagian ini berhubungan dengan BEUS point. Pengambilan point yang sudah didapat oleh pengguna diambil di bagian ini. Terdapat juga daftar-daftar bagaimana pengguna dapat mendapatkan BEUS point melalui misi.

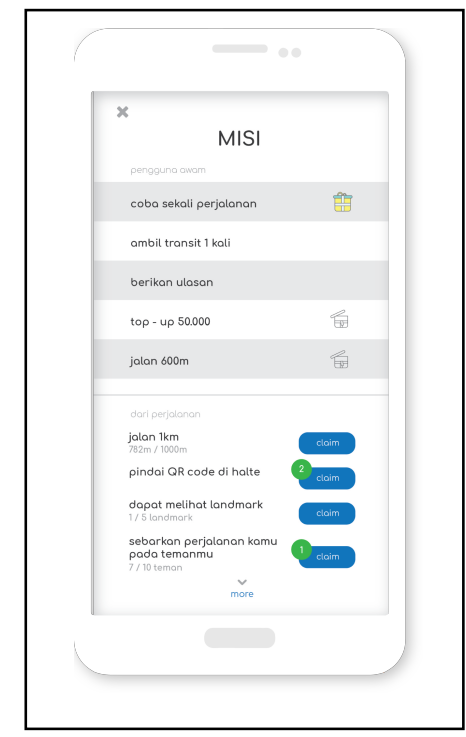

Gambar 6. Misi

(Sumber: Dokumen Pribadi, 2018)

Pengaturan akun pribadi merupakan menu yang dapat mengatur penempatan alamat rumah atau alamat lainnya yang berfungsi pada bagian quick access pada bagian menu utama.

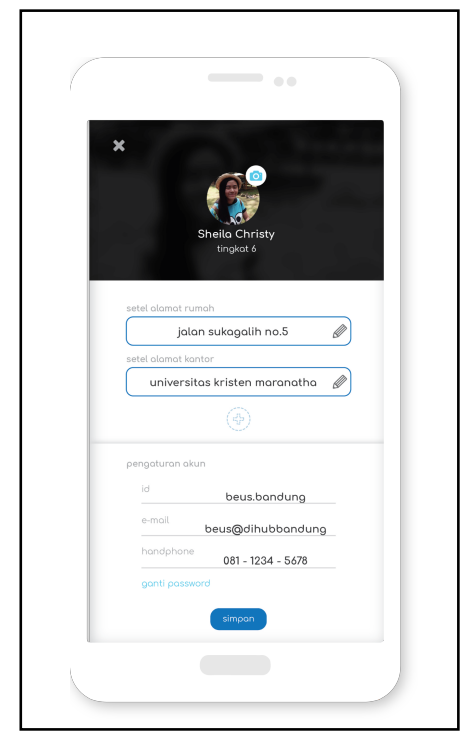

Gambar 7. Pengaturan akun (Sumber: Dokumen Pribadi, 2018) 
Serat Rupa Journal of Design, January 2019, Vol.3, No.1: 34-47

E-ISSN: 2477-586X, ISSN: 2338-3348 | https://doi.org/10.28932/srjd.v3i1.1060| Received: 02-10-2018, Accepted: 25-01-2019 Sheila Christy, Roy Antonius Susanto

Perancangan Media Aplikasi Bus Trans Metro Bandung

Menu ini dapat diakses pada setiap bagian yang terdapat icon garis tiga buah. Terdapat menu tambahan lainnya seperti: apps setting, rate us, feedback, report online, social link, share, dan term of service.

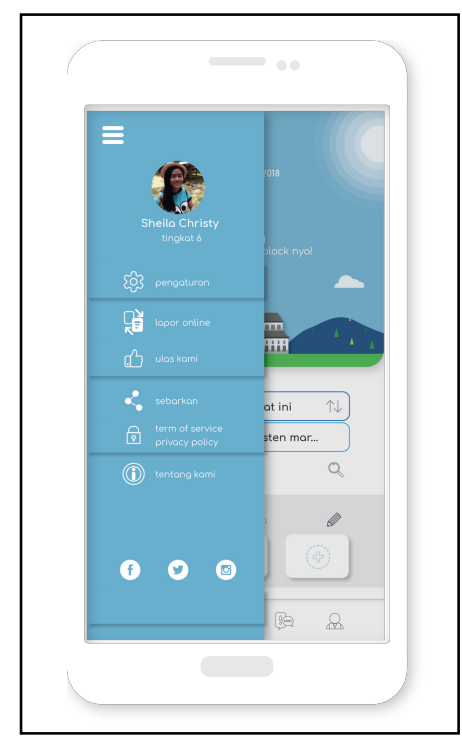

Gambar 8. Side menu

(Sumber: Dokumen Pribadi, 2018)

Untuk mempromosikan aplikasi yang telah dibuat, tentunya harus ada media pendukung yang membantu sosialisasi aplikasi tersebut. Gaya visual yang dibuat menyesuaikan tampilan aplikasi serta dibuat satu seri agar terlihat menjadi satu kesatuan sehingga target audience lebih mengingat aplikasi BEUS ini. Berikut tampilan media-media pendukung yang sudah dipilihkan sesuai kebutuhan.

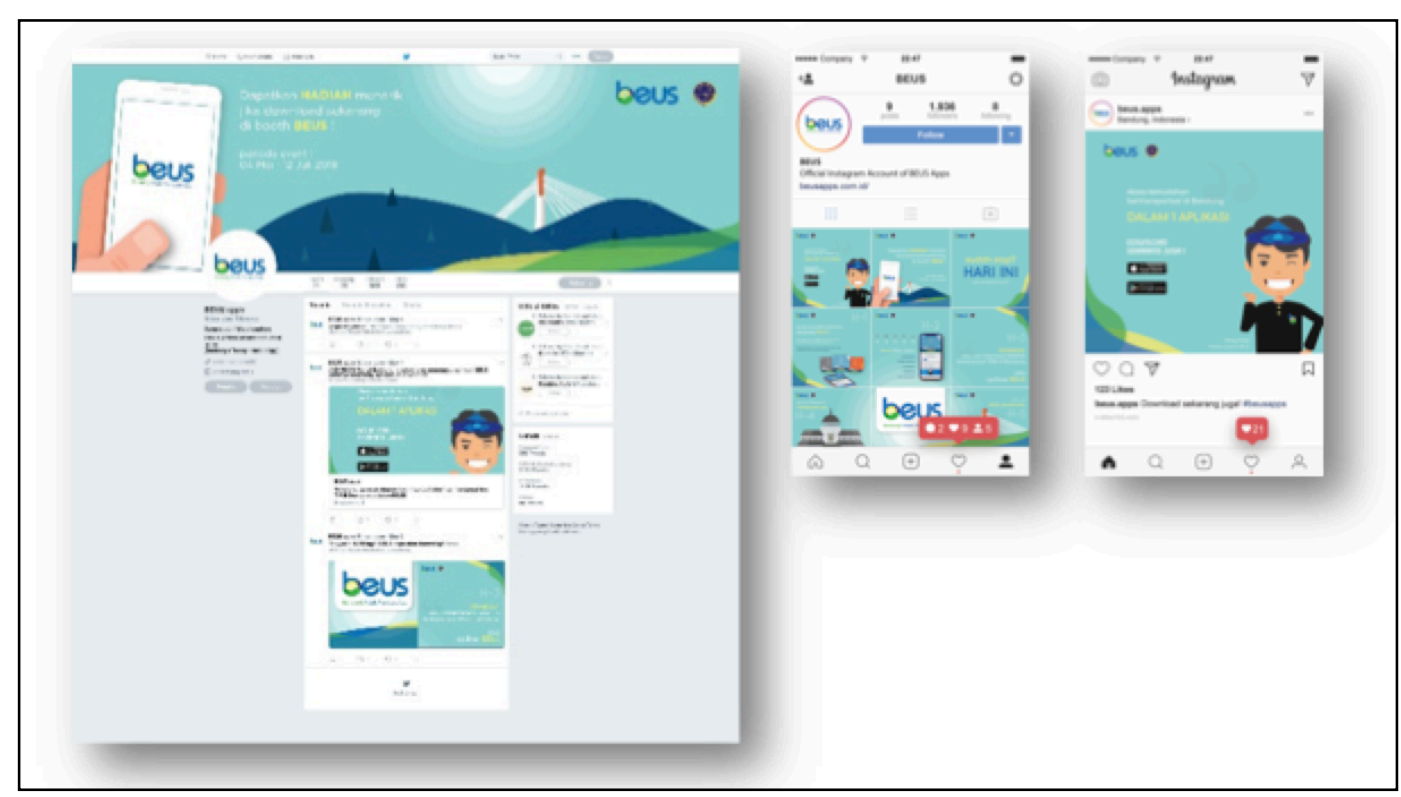

Gambar 9. Social media advertising - Twitter (Sumber: Dokumen Pribadi, 2018) 
Serat Rupa Journal of Design, January 2019, Vol.3, No.1: 34-47

E-ISSN: 2477-586X, ISSN: 2338-3348 | https://doi.org/10.28932/srjd.v3i1.1060 | Received: 02-10-2018, Accepted: 25-01-2019 Sheila Christy, Roy Antonius Susanto

Perancangan Media Aplikasi Bus Trans Metro Bandung

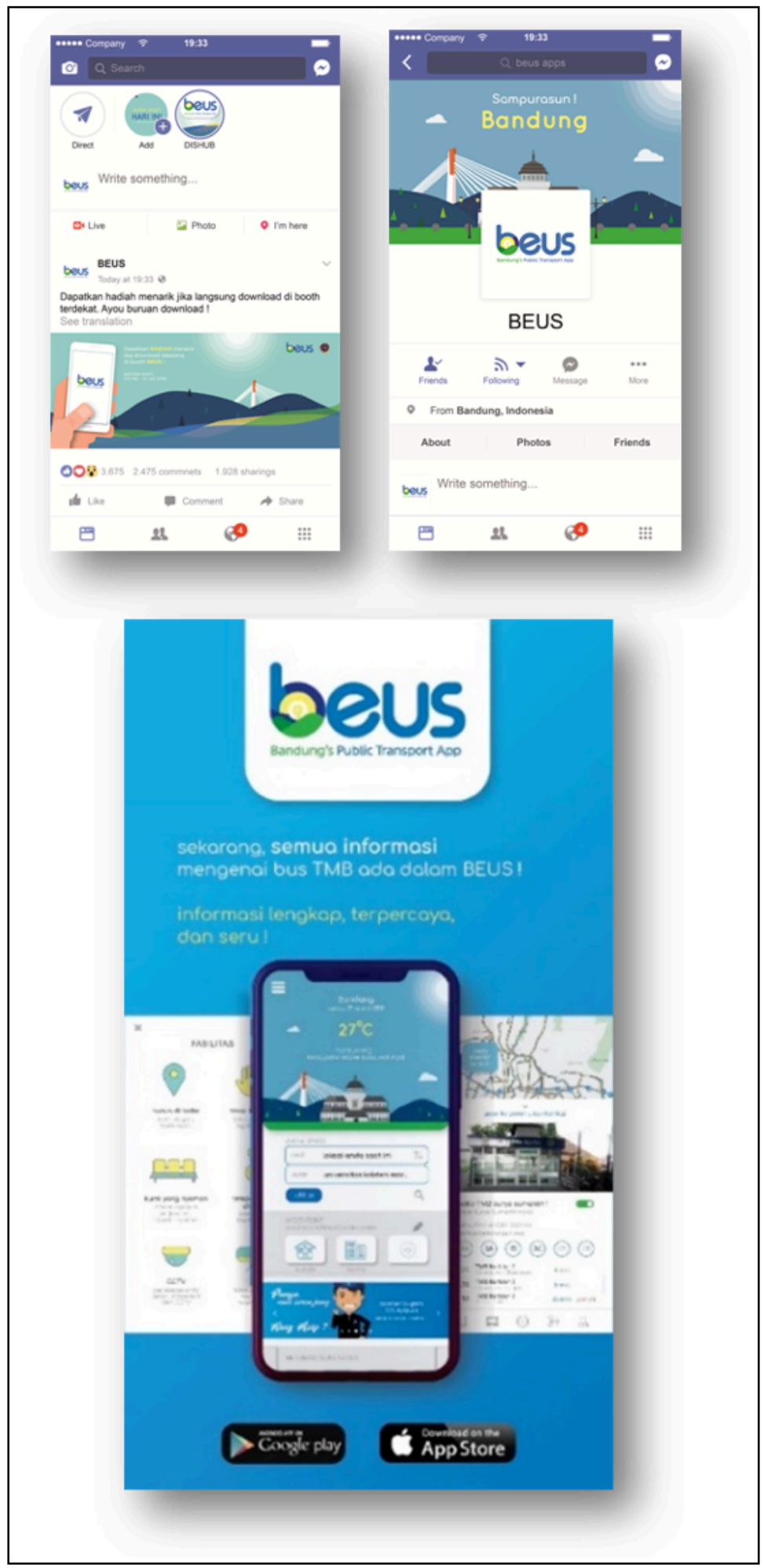

Gambar 10. Social media advertising - Facebook

(Sumber : Dokumen Pribadi, 2018) 
Serat Rupa Journal of Design, January 2019, Vol.3, No.1: 34-47

E-ISSN: 2477-586X, ISSN: 2338-3348 | https://doi.org/10.28932/srjd.v3i1.1060| Received: 02-10-2018, Accepted: 25-01-2019 Sheila Christy, Roy Antonius Susanto

Perancangan Media Aplikasi Bus Trans Metro Bandung

\section{PENUTUP}

Secara tidak langsung kemajuan teknologi saat ini sudah sangat berkembang, namun sayang masih tidak digunakan secara maksimal oleh salah satu transportasi publik milik pemerintah Kota Bandung yaitu Bus Trans Metro Bandung (TMB). Setelah dilakukan observasi serta penelitian ilmiah lainnya, masih banyak masyarakat yang kesulitan menggunakan bus TMB sebagai transportasi sehari-hari karena kesulitan mendapatkan informasi seputar bus TMB.

Kurangnya kesadaran masyarakat Kota Bandung untuk menggunakan transportasi umum dan lebih memilih untuk menggunakan kendaraan pribadi sehingga menciptakan kebiasaan masyarakat Kota Bandung yang ingin serba enak (menyadari bahwa transportasi pribadi tentunya lebih mudah dibanding transportasi umum), menjadi salah satu kesulitan dalam menyadarkan masyarakat Kota Bandung sisi positif dari menggunakan transportasi umum untuk kegiatan sehari-hari.

Oleh karena itu, penyediaan aplikasi yang memuat seluruh informasi mengenai bus TMB diharapkan dapat memudahkan masyarakat dalam mencari informasi, serta memudahkan masyarakat dalam menggunakan bus TMB sebagai transportasi sehari-hari yang ke depannya berdampak pada peningkatan minat masyarakat utnuk menggunakan bus TMB

\section{DAFTAR PUSTAKA}

Acuan artikel dalam jurnal:

Aditya, Indra. 2016. Partisipasi Masyarakat Dalam Perencanaan Trans Metro Bandung dan Monorel di Kota Bandung. Karawang : Jurnal Politikom Indonesiana. 1(2), 85-87

Hilmi, Rofid. Ardiansyah. Pengembangan User Ecperience dan User Interface Aplikasi Igometer Taksi. Yogyakarta : Jurnal Sarjana Teknik Informatika. 1(2).

Nasution, A. 1996. Manajemen Transportasi. Jakarta: Ghalia Indonesia.

N. Uday Bhaskar, P. Prathap Naidu, S.R. Ravi Chandra Babu, P.Govindarajulu.2011. International Journal of Software Engineering (IJSE), 2(3).

Acuan dari dokumen online:

Pemkot Bandung Mulai Konversi Armada Angkot Menjadi Bus. Diambil dari: https://news.okezone.com/read/2016/06/06/525/1407460/2017-pemkot-bandungmulai-konversi-armada-angkot-menjadi-bus 